\title{
EL PRINCIPIO DE RESPONSABILIDAD DE HANS JONAS A LA LUZ DE LA CONCIENCIA ECOLÓGICA
}

\author{
Germán González Gómez \\ Universidad de Santiago de Compostela
}

http://dx.doi.org/10.5209/rev_NOMA.2015.v46.n2.51421

\begin{abstract}
Resumen.- Estamos inmersos en una era tecnológica en la que el ser humano tiene el poder y se vanagloria de ello, de dominar a su antojo la naturaleza. Es un poder de tales dimensiones e implicaciones que exige imperiosamente de un nuevo saber que lo combata: posiblemente, una ética de capacidad predictiva como la delprincipiode responsabilidad de Hans Jonas. La promesa del progreso tecnológico ha devenido en amenaza; sus consecuencias medioambientales han propiciado la aparición de la llamada conciencia ecológica, cuya concreción teórica conforma la ecoética. El vínculo entre ambas éticas se evidencia en elprincipio de precaución, una actitud de alerta y freno ante los riesgos de la actual civilización tecnocientífica.
\end{abstract}

Palabras clave.- Conciencia ecológica, ecoética, Hans Jonas, Principio de responsabilidad, Principio de precaución

\begin{abstract}
Today we are immersed in a technological era in which human being has the power to dominate nature at will -a power that he prides himself on. This power has got such great dimensions and implications that a new knowledge is strongly required to counter it: possibly, an ethics with predictive power such as Hans Jonas's imperative of responsibility. The promise of technological progress has become a threat and its environmental consequences have facilitated the emergence of the ecological awareness, giving rise to eco-ethics as its theoretical realization. The link between both ethics is evidenced in the precautionary principle, an attitude of alertness and constraint against the risks of the current technoscientific civilization.
\end{abstract}

Keywords.-Environmental awareness, eco-ethics, Hans Jonas, Imperative of Responsibility, Precautionary Principle

\section{La conciencia ecológica}

La sensibilidad hacia la naturaleza se hace más visible tras la Segunda Guerra Mundial. Se empiezan a considerar los efectos adversos que sobre el medioambiente ha producido la guerra y el progreso en el proceso productivo. Se trata de la actividad industrial militar y civil, dela minería, la agricultura, la ganadería, la industria química y farmacéutica, etc.,y el transporte. También asistimos a un cambio de época, en la que la política se pone al servicio de la economía y en la que ésta se va a basar cada vez más en el consumo que en la producción. Sus cada vez más estudiadas secuelas-la contaminación química, acústica y hasta radiactiva de la superficie terrestre, de sus aguas y atmósfera, iniciadas en los países más desarrollados y extendidas al resto del planeta- refuerzan la idea de un deterioro imparable ${ }^{1}$. En 1962 Rachel Carson hacía esta denuncia:

\footnotetext{
${ }^{1}$ Tan imparable como que la contaminación química ya alcanza el aire de las cumbres más elevadas como el Everest o de profundos mares como las fosas abisales. Pero todo empezó bien cerca: el deterioro que se cernía en Occidente -con las tan visibles consecuencias para la salud de las personas- acabó por impulsar la denuncia de cada vez más voces, de nuevas
} 
Durante el último cuarto de siglo, este poder [el de alterar la naturaleza por parte del ser humano] no sólo se ha incrementado hasta una inquietante magnitud, sino que ha cambiado en características. El más alarmante de todos los atentados del hombre contra su circunstancia, es la contaminación del aire, la tierra, los ríos y el mar con peligrosas y hasta letales materias. Esta polución es en su mayor parte irreparable; la cadena de males que inicia, no sólo en el mundo que debe soportar la vida, sino en los tejidos vivos, en su mayor parte es irrecuperable. En esta contaminación, ahora universal, del medio ambiente, la química es la siniestra y poco conocida participante de la radiación en el cambio de la verdadera naturaleza del mundo... la verdadera naturaleza de su vida. El estroncio 90, liberado en el aire por las explosiones nucleares, llega a la tierra con la lluvia o cae por sí solo (...) De igual modo, los productos químicos se diseminan por los sembrados, o por los bosques, o por los jardines, se alojan durante largo tiempo en las cosechas y penetran en los organismos vivos, pasando de uno a otro, en una cadena de envenenamiento y de muerte. O se infiltran misteriosamente por los arroyos subterráneos hasta que emergen mediante la alquimia del aire y el sol, se combinan en nuevas formas que matan la vegetación, enferman al ganado y realizan un desconocido ataque en aquellos que beben de los antaño puros manantiales. Como dijo Albert Schwitzer: "El hombre difícilmente puede reconocer los daños de su propia obra". ${ }^{2}$

El libro de Carson, de 1962, es para muchos el punto de partida de la conciencia ecológica. En cualquier caso ayudó de forma decisiva a la toma de conciencia junto a otro hito como fue la creación, un año antes, del Fondo Mundial para la Naturaleza (WWF). Pero no podemos olvidar la creación de la Unión Internacional para la Conservación de la Naturaleza y sus Recursos Naturales (UICN) en 1948, evidenciándose así el incipiente interés ético-político por los problemas ecológicos. Paralelamente a estos hechos, HannahArendt, es la primera, desde el mundo del conocimiento, en advertirnos del riesgo existente para la esencia del ser humano con la publicación de La condición humana en 1958, cuestión que culminará Hans Jonas en 1979 con la obra objeto de nuestro análisis, El principio de responsabilidad. Ensayo de una ética para la civilización tecnológica.

La activa sensibilidad ética hacia la naturaleza, hacia los peligros y consecuencias del sistema productivo ydel consumo-en general, el resultado de la tecnociencia sobre los equilibrios ecológicos de nuestro planeta-

organizaciones de protección de la naturaleza, de movimientos sociales y organizaciones ecologistas, alertando y criticando la acción criminal del ser humano hacia la naturaleza, como veremos en las siguientes líneas. Diferentes organismos nacionales e internacionales comenzaron a aportar medios físicos y humanos para ponerle freno. Pero hoy, con más concienciación que nunca antes, con los avances en materia medioambiental ocurridos en los últimos años en los países más desarrollados, las consecuencias de la invención humana siguen fuera de control. Es un tema, por ello, el de la crisis ecológica, el de las consecuencias de la tecnología, de absoluta actualidad. Y no sólo por lo que se sabe que se podría hacer mejor, sino porque hay cosas que aún no se saben. Por poner un ejemplo, pensemos en las depuradoras, con la dilatada historia que tienen por detrás: éstas no son capaces de identificar y cribar el desecho de medicamentos. ¿Cuáles serán las consecuencias de esto? Están aún por determinar. La reflexión filosófica está servida.

${ }^{2}$ (1964) CARSON, Rachel, Primavera Silenciosa, Luis de Caralt Editor, Barcelona, p. 18. 
,cristalizará al iniciarse la década de los setenta, con la instauración del Día de la Tierra en los Estados Unidos y con la creación, en1971, de la organización Greenpeace. Aunque, tal vez el hecho más relevante se produceun año después con la publicación del influyente y alarmante informe Meadows, Los límites del crecimiento, que había sido encargado en 1968 por el Club de Roma con motivo de su constitución. En él se advierte de los peligros del desatado y voraz industrialismo y productivismo, de los límites de dicho crecimiento económico ante la finitud de los recursos y materias primas del planeta. Es el momento en el que se celebra la primera Conferencia de la Organización de las Naciones Unidas sobre el medio ambiente y es también el comienzo del movimiento ecologista internacional ${ }^{3}$.

A partir de estos años, la problemática ecológica va a ser afrontada, por un lado, a través de conferencias y acuerdos intergubernamentales y, por otro, con la denuncia y las reivindicaciones de diversos movimientos sociales y organizaciones ecologistas abogando por un modelo alternativo, más sostenible y justo ${ }^{4}$. Se han ido celebrando multitud de eventos para impulsar un cambio en las políticas económicas desarrollistas; cambios, a día de hoy, muchos inexistentes, otros poco apreciables y efectivos y, en general, siempre por detrás de los acontecimientos.

En ese contexto, el pensamiento ecológico ha ido evolucionando, ya sea en su vertiente teórica como en la vertiente práctica, al compás del creciente agravamiento de la crisis ecológica (deforestación, contaminación "por tierra, mar y aire", desertización, pérdida de biodiversidad, merma de la productividad de las tierras de cultivo, agotamiento de los bancos marinos, avance de la agricultura y ganadería intensivas y transgénicas...) planteando nuevos retos teórico-prácticos a una sociedad que ha empezado a cobrar conciencia de la extrema fragilidad vital y existenciala la que le ha conducido suacción civilizatoria. Acción basada en unaciencia ${ }^{5}$ de la que se deriva una tecnología que se ha desarrolladoa gran escala en el último siglo.La aceleración en el ritmo de losdescubrimientos e invenciones, su inercia y progresiva autonomía yel consiguiente poder de alteración y destrucción de los equilibrios

\footnotetext{
${ }^{3}$ Cfr. RODRÍGUEZ RIAL, Nel y BARCIA GONZÁLEZ, Javier (2011), “Introducción. La génesis histórica de la conciencia de la crisis ecológica y su insostenibilidad". En BARCIA GONZÁLEZ, Javier (ed.), A razón ecolóxica, Santiago de Compostela, Servicio de Publicacións da Universidade deSantiago de Compostela, pp. 7-20. Para una genealogía de cómo el problema ecológico ha ido permeando el pensamiento ético en Occidente, cfr. LA TORRE, María Antonia (1993), Ecología y moral. La irrupción de la instancia ecológica en la ética de Occidente, Desclée de Brouwer, Bilbao.

${ }^{4}$ A pesar de la pretensión del movimiento ambientalista de un crecimiento sostenible, con la adopción del concepto 'sostenible' por parte del nuevo marketing, éste ha perdido buena parte de su significado inicial y, por tanto, prestigio. El término 'sustentable' se empieza a generalizar pues parece ser más adecuado para referirse a un modo de crecimiento (incluso de decrecimiento), el desarrollo de una sociedad que no esté a merced del mercado, sino al contrario.

${ }^{5}$ Una ciencia fría, permeada aún por el viejo positivismo que no acaba de morir. Se trata de la herencia viva de "una 'ciencia sin sujeto' en la que la subjetividad no tenía cabida". Cfr. PINTOS PEÑARANDA, M. Luz (2004), "La fenomenología y las ciencias humanas y bisosociales. Su convergencia en un importante momento de cambio de paradigmas", Philosophica, 27, p. 217.
} 
ecológicos, han puesto a la naturaleza contra las cuerdas y al mismo homo sapiens sin saber cómomanejar semejante situación ${ }^{6}$.

Claro que para pretender tomar el control perdido antes hay que conocer biena esatecnocivilización. Podríamos decir, con Ortega, que "lo que nos pasa, es que no sabemos lo que nos pasa". Afirmación que también hoy podríamosampliar a que "lo que nos pasa, es que no queremos saber lo que nos pasa". Se puede alegar, sin embargo, que el mundo industrial tardío ha alcanzado tal complejidad en todos sus campos y estructuras que la creciente especialización de los saberes y prácticas conseguida a lo largo de los tiempos modernos tampoco ayuda a que las élites ilustradas-especializadas $-\mathrm{y}$, mucho menos, el resto de ciudadanos-, tengan ideas claras sobre "lo que pasa", una información fiable y veraz sobre lo que "realmente" pasa. Los mass media utilizan, cada vez más, una realidad virtualizada donde los acontecimientos son manipulados y seleccionados, publicitados o escondidos en función de los intereses del poder ideológico y financiero. Aquí convendría recordar el viejo dicho de que "en una guerra -y esta guerra "verde" lo es- la primera víctima es la verdad». Aunque la educación y la libertad de información han sido hasta ahora las vías para una creciente concienciación, esto es algo queestá siendo amortiguado por el enorme peso de los grupos económico-financieros y sus lobbies, que tienen una gran influencia sobre buena parte de las instituciones científicas y comités nacionales e internacionales de control y evaluación de riesgos.

La génesis de la concienciaecológica tampoco es ajena al fuerte desarrollo que conoce la ecología como ciencia a comienzos de los años setenta ${ }^{7}$, revelando algo que el ser humano actual -el hombre moderno- se ha empeñado en olvidar: que la economía humana es un subsistema de ese otro gran conjunto que es la Naturaleza, con mayúsculas. Las raíces del problema económicoecológico, de alguna manera, se hallan ya en Malthus, cuando advierte de la desproporción entre el crecimiento geométrico de la población mundial respecto del crecimiento aritmético de los recursos y alimentos. Hoy en día, aun con una masa de población excesiva yen continuo crecimiento -se diría que sin techo a la vista-, parece tendente a moderarse ${ }^{9}$. Los avances de la tecnociencia en prevención de catástrofes naturales, maquinaria y cultivoses

\footnotetext{
${ }^{6}$ La escala que ha alcanzado la técnica a lo largo de la modernidad hace pensar a Jonas que tal vez ésta supere la capacidad de resistencia del finito y estrecho espacio planetario en el que tal inmenso poder se desenvuelve "Tenemos que añadir ahora que hoy en día toda aplicación de una capacidad técnica por parte de la sociedad (aquí el individuo ya no cuenta) tiende a crecer hacia la "gran escala". La técnica moderna tiende íntimamente al uso a gran escala y quizá se vuelva demasiado grande para el tamaño del escenario en el que se desarrolla -la Tierra-, y para el bien de los actores -los seres humanos." JONAS, Hans, (1997), “¿Por qué la técnica moderna es objeto de la Ética?", en Técnica, medicina y ética, Madrid, Ediciones Paidós, 1997, p. 35.

7 Ejemplo de ello es la eminente obra Theentropylaw and theeconomicprocess de Nicholas Georgescu-Roegen, publicada en 1971. (Existe traducción al español, con una introducción y una recopilación bibliográfica de GRINEVALD Jacques (1986), La ley de la entropía y el proceso económico, Fundación Argentaria-Visor Distribuciones, Madrid.

${ }^{8}$ Cursivas nuestras. En lo sucesivo voy a utilizar el término hombre, en cursiva porque así ha sido traducido al castellano desde los textos de Jonas el término 'mensch', que significa 'ser humano', nunca sólo una mitad de los humanos, es decir, los hombres.

${ }^{9}$ China, el país más poblado del mundo, sería el caso paradigmático. África, es el caso contrario; de momento, es la zona del mundo con mayor potencial de crecimiento.
} 
verdad que revelan nuevas fórmulas para paliar parte de la falta de agua y tierra necesarias para el aumento de la producción agroalimentaria, la necesaria para mantener lo que muchos tildan de plaga humana; pero lo hacena expensas del orden natural, haciendo igualmente inviable la vida futura de la mayoría de las especies animales y vegetales que hoy sobreviven en la Tierra $^{10}$. Según Hans Jonas, el desarrollo de la tecnociencia, sobre todo de la ciencia y la técnica del siglo XX en su connivencia con el modelo productivo capitalista $^{11}$, es lo que ha llevado a la Tierra a la situación de crisis ecológica que conocemos. Estamos ante un modelo económico que no sólo ha explotado en exceso los territorios de los países ricos sino que ha actuado como un depredador, y sigue haciéndolo, con los territorios periféricos, en un ejercicio de creciente neocolonialismo globalizado. Realmente, vampirizamos de otros territorios las riquezas que disfrutamos, las que, por tanto,sobreconsumimos: la humanidad, hoy, hace uso de unos recursos equivalentes a 1,3 planetas como el nuestro ${ }^{12}$; a ello han contribuido sobre todo aquellos países enriquecidos del Norte y sus niveles de vida insostenibles ${ }^{13}$.

Pero estamos ante una explotación planetaria que, según Jonas, ya no cabe interpretar en la estrecha dialéctica amo-esclavo. No es sólo un dominio ejercido por los dueños de los medios de producción, es también una sobreexplotación de la Tierra en la que participan las fuerzas del trabajo que, de manera creciente, han ido elevando su poder adquisitivo y de consumo. Todos somos, pues, responsables de este sistema de dominio y explotación planetaria, facilitado en los últimos siglos por una "motorización" de la vida que ha permitido multiplicar exponencialmente la fuerza de trabajo del cuerpo humano para, así, poder exprimir la Tierra a un ritmo nunca imaginado antes de la revolución industrial, antes de la invención delos primeros motor. De todo ello se derivael tremendo impacto medioambiental, lastan negativas consecuencias

${ }^{10}$ Según la UICN, cada año se extinguen entre 10.000 y 50.000 especies en el planeta. www.wwf.es. Fuente consultada el 28 de agosto de 2015.

${ }^{11}$ Con ello, no olvidamos que los modelos centralizados de producción, comercialización y consumo de los países tras el telón de acero también operaron en el gran olvido del respeto al medioambiente. Sus economías que, dada su deficiente renovación tecnológica, contribuyeron especialmente en la década de los setenta y ochenta a polucionar y deteriorar el entorno natural, de manera tanto o más intensa que en Occidente. Como dice Hans Jonas, cuando aún se dejaban sentir efectos de la guerra fría, "hasta hoy el marxismo -'progresista' desde el comienzo, nacido bajo el signo del 'principio de esperanza' y no del 'principio del temor' no es menos fiel al ideal baconiano que el adversario capitalista". En "lo que al suministro de bienes se refiere, sin duda ha alcanzado mejores resultados el capitalismo, si bien al precio de un derroche que no puede ya permitirse". Una "burocracia funcional (...) no tiene nada que perder. La ausencia de riesgo es un alto precio a pagar por la desaparición del afán de lucro". "Lo único que no ofrece duda es que la eliminación del afán de lucro acaba al menos con un motivo para el derroche -la creación de necesidades artificiales de bienes nunca antes deseados y ni siquiera conocidos- (...) Sin embargo, las enormes consecuencias de los errores del centralismo, si se producen ( $\mathrm{y}$ han de producirse), se dan también en los casos de mayor autonomía y más perfeccionada burocracia; quizás, por eso mismo, aumentados". (1995) JONAS, Jans, El principio de responsabilidad. Ensayo de una ética para la civilización tecnológica, Herder, Barcelona, pp. 236-242. Y efectivamente, enormes consecuencias que de hecho se dieron como en el caso de Chernóbil.

${ }^{12}$ Cfr. VIVES-REGO, J. (2010), Los dilemas medioambientales del siglo XXI ante la Ecoética. Los grandes retos ecológicos de los políticos, las empresas y la ciudadanía. Bubok, Madrid.

${ }^{13}$ Un mal que se ha ido extendiendo a los países emergentes como China o Brasil, que están contaminando incluso a mayor nivel. 
que conocemos $-y$ las que no conocemos, muchas inimaginables e imprevisibles-, que definitivamente han modificado el escenario en el que ha de vérselas el conocimiento y el comportamiento humano.

\section{La responsabilidad, según Jonas}

Hans Jonaspropone una nueva ética que pretende responder a esos retos que la actual civilización tiene planteados. Su eminente y laureada obra, El principio de responsabilidad. Ensayo de una ética para la civilización tecnológica ${ }^{14}$, fue publicada en Alemania a finales de la década de los setenta, lugar en el cual había eclosionado precisamente la conciencia ecológica ${ }^{15}$.

Esta situación epocal y contextual, que hemos tratado de esbozar en el anterior parágrafo, junto con la novedad, la calidad filosófica de la obra y, sobre todo, la oportunidad y necesidad del momento, pueden explicar el rápido éxito que conquistó la obra ${ }^{16}$. En PR,Jonas nos explica que no podemos esperar milagros tecnológicos que en el futuro arreglen la degradación medioambiental actual, requiriéndose un cambio ético radical con la aplicación de principios como el que él propone, el principio de responsabilidad- que aseguren la esencia de la humanidad futura y la supervivencia de la naturaleza. Hay una creencia instalada en la sociedad actual: la confianza de que una nueva tecnología resolverá los problemas de una tecnología más obsoleta. Es ésta una concepción o interpretación optimista y de ribetes utópicos de la tecnociencia que ha sido apoyada por buena parte de científicos, técnicos e

\footnotetext{
${ }^{14}$ En lo que sigue, las referencias al texto en castellano Principio de responsabilidad se harán con la abreviaturaPR, y las referencias al mismo texto en su versión original alemana, PrinzipVerantwortung, con PV. Con esta publicación nos hallamos seguramente ante la mayor y más controvertida obra de la filosofía de la técnica, una ingente tarea intelectual que conforma una posible orientación para la humanidad. Hans Jonas bebió de las fuentes de la fenomenología: así, el análisis de la experiencia, la capacidad del sujeto en la representación del mundo o el distanciamiento de los hechos, estará todo ello presente a lo largo de toda su producción intelectual. En esta tardía obra que nos ocupa —en 1979, fecha de la publicación de PR, Jonas tenía 76 años - aun declaraba que: "deberíamos mantenernos abiertos a la idea de que las ciencias naturales no dicen toda la verdad acerca de la naturaleza" (PR: 35). No en vano, fue discípulo directo de Husserl. Aunque, sin olvidar también a Bultmann, quien contribuyó a sus trabajos sobre gnosticismo, la huella más profunda, reconocida por el mismo Jonas, será la de Heidegger. Con todo, se alejará de este último filósofo, aunque realmente más en lo político que en lo filosófico. Como indica Wolin, "al atreverse a afrontar directamente el nazismo de Heidegger y -lo que en la época era todavía más polémico [1964]- tratar de vincular directamente el error político del filósofo con las deficiencias de su pensamiento, Jonas hizo gala de la inquebrantable integridad moral que habría de ser rasgo distintivo de su vida y de su obra". (2003) WOLLIN, R., Los hijos de Heidegger. Hannah Arendt, Karl Löwith, Hans Jonas y Herbert Marcuse, Ediciones Cátedra, Madrid, p. 161. Para nuestro interés, subrayar que su investigación se decantará hacia el humano viviente en el seno de un mundo cargado de sentido, partiendo de la síntesis entre una filosofía de la materia y una filosofía de la mente que le llevará a la filosofía de la técnica de la que aquí hace gala, en PR.

${ }^{15}$ Fue el país germano una de las naciones, junto a los Estados Unidos, donde más desarrollo alcanzó la conciencia ecológica y de manera más temprana. También, conviene recordar que Die Grüne, el partido alemán de Los Verdes, se constituyó precisamente en el año 1980.

${ }^{16}$ El elogio que le brindó su compañera de estudios - condiscípula de Heidegger y también colega en la New School- Hannah Arendt, puede ilustrar el impacto que El principio de responsabilidad causó en las conciencias más despiertas e ilustradas de la época: "¡Hans, éste es el libro en el que estaba pensando Dios cuando lo creó a usted!".
} 
inventores ${ }^{17}$; todos ellos defensores de su neutralidad axiológica, defensores de la ausencia de implicaciones morales en las invenciones y creaciones tecnológicas o biomédicas. El problema, según los que así piensan, estribaría tan solo en la utilización y aplicación de esas herramientas. Pero hay otra tradición crítico-filosófica -aquélla que se inspira de manera eminente en la Escuela de Frankfurt- que entiende que ${ }^{18}$, ante los comprobados efectos de la tecnología en la biosfera, ya no cabe argüir la pretendida, pero no real, imparcialidad cognitiva y neutralidad axiológica y ética. Nuestro autor critica la ceguera de la tecnociencia respecto de su siempre "interesado compromiso" cognitivo, teórico y práctico: los conocimientos e inventos tienen usos pragmáticos que obedecen a necesidades e intereses, objetivos y propósitos particulares de los individuos y grupos que crean o hacen uso de tales conocimientos o inventos. Sabemos bien que cuando los utiliza el sistema productivo, lo que busca con ellos es el lucro económico y no el bien común.

Con todo, entendemos la tesis de partida del Principio de responsabilidad, que la promesa de la técnica moderna de crearnos un "mundo feliz" a través del dominio, sometimiento y uso de la naturaleza se ha convertido más bien en una amenaza $^{19}$. No se trata sólo de una amenaza física venida desde fuera, sino también de un nuevo reto interno al hombre;afecta a la propia naturaleza humana. Está en juego la capacidad del ser humano de dar respuestas justas ante la modificación profunda que está sufriendo su esencia.

La aceleración de la moderna civilización, sus cada vez más cortos ciclos de revolución tecnológica,han creado un poder quese ha vuelto autónomo. Un poder -el derivado de las invenciones tecnobiológicas, consustanciales a una fórmula sobre-explotadora de habitar la Tierra- que hatrastocado las relaciones entre la humanidad y la naturalezaademás de haber supuesto también un hondo cambio en la conciencia del hombre,coextensiva con el nihilismo reinante ${ }^{20}$, sobreviniéndole un nuevo y desasosegante sentimiento: el

\footnotetext{
${ }^{17}$ Jonas es muy crítico con los utopismostecnocientíficos y con los mesianismos políticos que florecen frente al nihilismo reinante: con medios seculares y no éticos pretenden establecer la condición de integridad perdida por los vaivenes de la modernidad, prometiendo -en el caso del comunismo, fascismo o el nacionalismo - un paraíso político para la humanidad.

18 Recordemos la obra de HABERMAS Jügen (1968), Erkenntnisundlnteresse, SuhrkampVerlag, Frankfurt am Main.

19 "Lo que tenemos ante nosotros es una dialéctica del poder que sólo puede ser superada con un poder mayor y no con una quietista renuncia al poder. Pero el programa baconiano manifiesta de por sí, esto es, en su propia ejecución en la cumbre de su triunfo, su insuficiencia, más aún, su contradicción interna, al perder el control sobre sí mismo, pérdida que significa la incapacidad no sólo de proteger a los hombres de sí mismos, sino también a la naturaleza frente a los hombres. La necesidad de proteger ambas cosas ha surgido por las proporciones que ha alcanzado el poder en su carrera hacia el progreso técnico y que, paralelamente a su uso cada vez más inevitable, nos ha hecho incapaces de detectar el cese de la previsible y cada vez mayor acción destructiva que el progreso ejerce sobre sí mismo y sobre sus obras. La profunda paradoja -no sospechada por Bacon- del poder aportado por el saber radica en que, si bien ha conducido a algo similar a un "dominio" sobre la naturaleza (esto es, a su mayor aprovechamiento), ha llevado al mismo tiempo a su completo sometimiento a sí mismo. El poder se ha vuelto autónomo, mientras que sus promesas se han convertido en una amenaza" (PR: 235).

${ }^{20}$ El nihilismo es un clásico tema de la filosofía alemana, desde que Nietzsche hiciera un preclaro diagnóstico de él y desde que Heidegger lo recuperase también como uno de sus temas preferidos. En la obra de Jonas ocupa también un lugar privilegiado a la hora de establecer el diagnóstico de los males que aquejan a la modernidad. Efectivamente; siguiendo
} 
sentimiento de la fragilidad de la vida terrestre y de su propia vulnerabilidad ante los cambios que él mismo ha introducido en la Naturaleza, unos cambios que contieneninesperados e incontrolables efectos secundarios.

Esta es la cuestión,el hombre se enfrenta por primera vez a unas experiencias tan novedosas y de consecuencias tan imprevisibles que ante ellas la tradicional sabiduría no tiene respuestas. Las anteriores teorías éticas se quedan obsoletas, incapaces ante el reto derivado del inmenso poder de la civilización tecnocientífica, consustancial a sus creaciones. Aquéllas se revelan impotentes como para guiar nuestra conducta respecto del planeta. Porque ya no se trata de medir y regular normativamente la relación del mal entre hombres - o con uno mismo- como venían haciendo esas éticas, por tanto, de matriz antropocéntrica.Es más -como nos comenta Jonas-,la entidad "hombre" y su condición fundamental no son vistaspor la antigua ética como variables en su esencia o como objeto de una techné transformadora ${ }^{21}$. Si antes la relación del hombre con la capacidad productiva se entendía queposeía unas connotaciones éticamente neutras y no había necesidad de una planificación lejana, ahora todo eso ha cambiado. El mal ha saltado de nivel. En la base de la ruptura de la horizontalidad intersubjetiva humana, entre sujetos de igual dignidad, en la extensión de la problemática ética a toda la biosfera y al porvenir, están los comportamientos acumulativos que se derivan de la actual praxis técnica, donde la secular proximidad de los fines se ha alejado en el espacio y en el tiempo ${ }^{22}$. Por ello se impone la necesidad de una éticanuevaque tenga en cuenta todo eso que está en juego:las condiciones globales de la vida humana, del futuro remoto, de su supervivencia como especie.

La responsabilidad del viejo saber, la de los actos "bien-intencionados", "bienmeditados" o "bien-ejecutados", no abarcaba posibles efectos secundarios no conocidos. Sin embargo, ahora se abre un abismo entre la fuerza del saber previo y la fuerza de las acciones, generándose un nuevo problema ético y metafísico para el que no hay doctrina ni principios a los que agarrarse.

Sólo sabemos del carácter inconmensurable e impredecible de las consecuencias de la acción global humana, de su alto grado de peligrosidad. Por ello, de lo que se trata -al juicio de Jonas-, es de asumir la ignorancia como premisa ética, como reverso del deber de saber, para llegar al saber adecuado. Este saber es el de la ética de una nueva dimensión: la de un poder predictivo que guíe la vigilancia a la que debemos someter el poder de la

a Wolin: "La clave del sagaz diagnóstico que hace Jonas de la época moderna y sus fracasos se halla en la idea del nihilismo. El nihilismo moderno era principalmente un producto de la ciencia moderna. La ciencia había tenido tanto éxito en cuestionar y desenmascarar toda variedad de superstición y fe infundada que, al final, dejó a los hombres y mujeres sin nada que creer." WOLLIN R., op. cit., p. 169.

${ }^{21}$ PR: 29

22 "La limitación a la proximidad espacial y a la contemporaneidad ha desaparecido arrastrada por el ensanchamiento espacial y la dilatación temporal de las series causales que la praxis técnica pone en marcha incluso para fines cercanos. Su irreversibilidad, asociada a su concentración, introduce un factor novedoso en la ecuación moral. A esto se añade su carácter acumulativo: sus efectos se suman, de tal modo que la situación para el obrar y el ser posteriores ya no es la misma que para el agente inicial, sino que es progresivamente diferente de aquélla y es cada vez más el producto de lo que ya fue hecho. Toda la ética tradicional contaba únicamente con comportamientos no acumulativos". Ibid., p. 33. 
tecnociencia. Esto es absolutamente vital y necesario pues el acrecentado poder de creación y de invención humanas han traído consigo también, de forma paralela, un acrecentado poder de destrucción. La solución está en la ética de la responsabilidad, entendida como principio de responsabilidad. Éste consiste en un saber de carácter incondicional ${ }^{23}$ que no se basa, por todo lo dicho, ni en la inconsciencia ni en la buena fe ni en la reciprocidad.

Jonas subraya que el hecho de que por primera vez en la historia la humanidadamenace la vida en la Tierra y que, con ello, ponga en jaque su propia supervivencia como especie, resulta una gran novedad a la que se ha de enfrentar la ética, un verdadero novum que no puede obviar la reflexión ${ }^{24}$. Es este inmenso poder de destrucción el que obliga a renovar y a expandir los principios éticos ${ }^{25}$. Pero no se trata de que el bien máximo a preservar sea la vida sino que ésta debe ser preservada para garantizar la supervivencia de la humanidad presente y de las generaciones humanas futuras sobre la Tierra.ParaJonas, el valor o bien máximo es la existencia de esta especie animal distinguida ontológicamente por su libertad y autonomía, por su grado de autoconsciencia y responsabilidad, es decir, por su condición espiritual y moral. Un aspecto relevante de su obra es precisamente la fundamentación que hace desde la ética a la metafísica, pasando por el paso intermedio de una fenomenología ontológica de la vida, con el fin de argumentar razones acerca de por qué es un imperativo categórico el que la humanidad deba ser preservada en la Tierra.En el corazón de su argumentación metafísica aparece el hombre, al queno le está permitido apostar el futuro de la humanidad, poner en juego su existencia en razón de ningún otro bien o beneficio que pudiera alcanzar ahora o en el porvenir. Ninguna promesa de un mundo mejor, ningún "meliorismo" futuro, ningún disfrute hedonista del presente, apurando todo lo que la Tierra y la técnica puedan brindarnos, puede ser esgrimido si con ello se hipoteca el futuro de la humanidad:

\footnotetext{
${ }^{23}$ El origen de la idea de responsabilidad, lo que Jonas considera como el arquetipo de toda acción responsable "no es la relación entre adultos autónomos (la cual es origen de la idea de los derechos y deberes recíprocos), sino [la] relación -consustancial al hecho biológico de la procreación- con la prole necesitada de protección. Y éste siempre apremiante campo de acción es el lugar más originario de su ejercicio. Sin este hecho y sin la relación entre las generaciones vinculada a él no podría entenderse ni el origen del cuidado providente ni el origen de la solicitud altruista entre seres racionales, por muy sociales que sean (PR: 83).

${ }^{24}$ El punto de partida de la nueva ética de la responsabilidad es la revisión del concepto de naturaleza. La antigua concepción de la naturaleza era la visión de algo duradero, permanente, sometida a ciclos y a cambios que no rompían la aparente estabilidad, como sucedía con la pretérita acción del ser humano. No obstante, todo ha cambiado: "La naturaleza, en cuanto responsabilidad, es sin duda un novum sobre el cual la teoría ética tiene que reflexionar". Se pregunta Jonas si ello plantea una exigencia moral. De ser así, ello supondría "ampliar el reconocimiento de 'fines en sí mismos' más allá de la esfera humana e incorporar al concepto de bien humano en el cuidado de ellos. A excepción de la religión, ninguna ética anterior nos ha preparado para tal papel de fiduciarios; y menos aún nos ha preparado para ello la visión científica hoy dominante de la naturaleza. Esta visión nos niega decididamente cualquier derecho teórico a pensar en la naturaleza como algo que haya de ser respetado, pues la ha reducido a la indiferenciación de casualidad y necesidad y la ha despojado de la dignidad de los fines. $Y$, sin embargo, de la amenazada plenitud del mundo de la vida parece surgir una sorda llamada al respeto de su integridad". Ibid., pp. 33 y 35.

${ }^{25}$ Cfr. JONAS H. (1997), "Por qué la técnica moderna es objeto de la ética", en Técnica, medicina y ética. Sobre la práctica del principio de responsabilidad, Editorial Paidós, Barcelona, pp. 15-37.
} 
Se llega así a la comprobación —según Jonas- de que, entre las apuestas en juego, pese a toda su procedencia física, se halla una realidad metafísica, un absoluto que, por ser el bien más alto y más vulnerable encomendado a nuestra tutela, nos impone como primer deber su conservación. (PR:75)

Para Jonas es un deber incondicional (eineunbedingtePflicht) (PV: 80) de la humanidad el preservar su propia existencia como tal. Se puede hablar de derecho al suicidio individual, pero nunca de derecho al suicidio de la humanidad (PR: 80).De tal forma, no serán lícitos los experimentos, juegos ni apuestas tecnobiológicas o de cualquier otra naturaleza que pongan en riesgo la existenciapresente o futura de la humanidad. Este imperativo va a funcionar como un axioma de la ética jonasiana. El axioma ético del que este precepto recibe validez, nuestro autor lo expresa de la siguiente manera: "nunca es lícito apostar, en las apuestas de la acción, la existencia o la esencia del hombre en su totalidad" (ibid.,p. 80). Aunque ya se ha adelantado la cuestión, conviene reparar en lo excepcional y raro de la última parte de dicho axioma: la que habla de la esencia del hombre en su totalidad. Para Jonas no sólo se trata de preservar la existencia de la humanidad, sino también su "esencia"-lo que introduce un importante matiz. Se trata de que tanto los experimentos biológicos de manipulación genética comolos inventos biomecánicos que puedan implantarse en el hombre, sea en el presente sea en el futuro, no cambien y alteren tal esencia, la cualJonas sitúa en la libertad, autonomía, piedad, sentido moral y responsabilidad. Esta última, la responsabilidad, es a la que apela Jonas para preservar la misma esencia y existencia presente y futura de la humanidad. La responsabilidad presente es la que ha de garantizar la libertad futura, esto es, que el futuro permanezca abierto para las generaciones venideras. De ahí los imperativos que nuestro autor sienta en El principio de responsabilidad: "obra de tal modo que los efectos de tu acción sean compatibles con la permanencia de una vida humana auténtica en la Tierra"; o expresado negativamente: "Obra de tal modo que los efectos de tu acción no sean destructivos para la futura posibilidad de esa vida"; o, simplemente: "No pongas en peligro las condiciones de la continuidad indefinida de la humanidad en la Tierra"; o, formulado finalmente, de nuevode forma positiva: "Incluye en tu elección presente, como objeto también de tu querer, la futura integridad del hombre" ${ }^{26}$. Se trata, pues, de no cerrar, con un abuso de las posibilidades del presente, las posibilidades del futuro; de no mancillar y destruir esa sacra res que es el hombre para Jonasni tampoco su futura existencia ${ }^{27}$.

Hemos de conjurar todo riesgo y toda acción que introduzcan incertidumbre sobre la existencia futura del hombre en la tierra. En este sentido, Jonas invierte el significado del principio cartesiano de la duda, haciendo un uso nuevo y de una extrema virtualidad de la duda:

\footnotetext{
${ }^{26}$ Ibid., p. 40.

27 "En la medida en que nos desvela algo «sagrado», es decir, algo que en ninguna circunstancia hay que violar (y esto es algo que puede aparecer a los ojos aun sin una religión positiva), el respeto nos impedirá mancillar el presente en aras del futuro, impedirá que pretendamos comprar éste al precio de aquél". Ibid., p. 358.
} 
Según Descartes, para comprobar lo indiscutiblemente cierto debemos equiparar todo lo que despierte alguna duda a lo manifiestamente falso. Aquí, por el contrario, a efectos de la decisión, debemos tratar lo dudoso, pero posible -cuando es de un determinado tipo-, como si fuera cierto. (PR: 80)

Se trata de dar la fuerza de la certeza a los posibles desastres, de los cuales no cabe certeza sino más bien duda;o lo que es lo mismo, de dar la fuerza de la certeza a lo que nos resulta dudoso pero puede ser posible. En especial, al riesgo para la esencia del hombre, y esto de una manera que explicamosmás adelante, dándole prioridad al sentimiento del temor:

Lo paradójico de nuestra situación consiste en que el respeto perdido hemos de recobrarlo a través del estremecimiento; lo positivo, a través de lo negativo; el respeto a lo que el hombre fue y es, a través del estremecimiento retrospectivo ante lo que podría llegar a ser y ante la mirada que tal posibilidad clava sobre nosotros desde el futuro pensado de antemano. En la medida en que nos desvela algo "sagrado», es decir, algo que en ninguna circunstancia hay que violar ( $y$ esto es algo que puede aparecer a los ojos aun sin una religión positiva), el respeto nos impedirá mancillar el presente en aras del futuro, impedirá que pretendamos comprar éste al precio de aquél. (Ibid., p. 358)

La inversión que Jonashace del principio cartesiano es con una específica finalidad disuasoria: la de que no caigamos en la tentación de apostar el futuro "infinito" de la humanidad por un bien finito: el de un presente vivido en la opulencia y hedonismo irrestricto. Apostar por la nada (la desaparición de la entera humanidad) frente a todo - esto es, frente al ser y la existencia- es una pésima apuesta. $Y$ es entre los extremos de una esperanzada utopía salvadora ${ }^{28}$ y de un pesimista desastre apocalíptico irremediabledonde se sitúa Jonas, defendiendo criterios de precaución y de responsabilidad ética. Se trata de una concepción anti-utópica del obrar humano y de la historia: el progreso indefinido no está asegurado; la idea moderna de la que la humanidad mejora con cada nuevo descubrimiento o invento es una falsa creencia que hace que aflojemos las clavijas de la prudencia.

\footnotetext{
${ }^{28}$ Utopía que no es plenamente consciente de las amenazas que se ciernen en el seno de la actual civilización tecnológica, caso de ErnestBloch y su obra El principio Esperanza. La crítica a la utopía es uno de los aspectos más relevantes de El principio de responsabilidad. Buena parte del capítulo $\mathrm{V}$, en concreto los apartados "La utopía del "hombre auténtico" venidero" y "La utopía y la idea de progreso" y todo el capítulo VI, cuyo título es bien significativo: "La crítica de la utopía y la ética de la responsabilidad", son pruebas suficientes de la importancia que Jonas daba a desmontar esa creencia utópica que él consideraba tan dañina para que, en el hombre de nuestro tiempo, pudiese instalarse una "heurística del temor" y un sentido de la responsabilidad ante los desastres presentes y las amenazas que se cernían sobre el futuro de la humanidad.

Jean Greisch, traductor de esta obra de Jonas al francés y autor de un breve texto de "Presentation", reconoce que El principio de responsabilidad debe no sólo la inspiración de su título a la obra de Bloch, sino que es contra éste que Jonas dirige todo su argumentario de la primera parte de El principio de responsabilidad: "Ilfautd'ailleursrappelerqu'ErnestBloch, dont la PrincipeEspérance non seleument forme le principal adversairequi domine toute la dernièrepartie de cetouvrage, maisqui a déjàcontribué à forger le titre [...]" (1992) GREISCH Jean, "Presentation". En Jonas H., Le principeresponsabilité. Une éthiquepour la civilisationtechnologique, Les Éditions du Cerf, Paris, p. 11.
} 


\section{La heurística del temor y la profética de la catástrofe}

Falsa creencia, por tanto, la de la fe en el progreso indefinido. Únicamente la podemos neutralizar y vencer a través de una representación imaginante del mal o de lo negativo que se incuba en la historia. Un mal que, sin hacerse todavía explícito y claro, amenaza nuestro futuro más inmediato y provoca, o debiera provocar en nosotros, un sentimiento de miedo o de temor que, a juicio de Hans Jonas, tiene notables virtualidades preventivas. Estaespecífica ética del riesgo predica el deber de la autolimitación y del autocontrol ante las amenazas y riesgos que provocan las nuevas tecnologías ${ }^{29}$.

Arribamos, pues, a la heurística del temor, que es una de las ideas más originales de Jonas y que le distancia de las clásicas teorías de la "prudencia" (phrónesis), de inspiración aristotélica. No se trata ya de esta vieja virtud de la sophía-que era, como sabemos, una sabiduría práctica, no teórica: una sabiduría o "habilidad" a la hora de saber comportarse y elegir la más correcta acción ante un hecho nuevo o una situación particular que sobreviniese en nuestra vida. Se trata más bien de la sabiduría propia, inmanente al miedo y al temor, que va a informar la teoría ética de la responsabilidad. En esto Jonas se opone también a las filosofías clásicas sobre los sentimientos del miedo o del temor (fobos) que interpretaban a éste como una emoción patológica que oscurecía la conciencia, paralizaba la voluntad y perturbaba el ánimo. Es decir, para aquellas viejas filosofías, el temor mermaba la capacidad reflexiva y volitiva del individuo, obstaculizando la buena deliberación, decisión y acción; era algo que, en definitiva, impedía el ejercicio de la responsabilidad.

La rehabilitación cognitiva que Jonashace del temor es uno de los aspectos másllamativos de su pensamiento frente a esta vieja tradición que le negaba dicho poder. El miedo o temor cumple una función heurística: nos descubre el bien a preservar a través del sentimiento (de miedo/temor) que nos produce el mal imaginado. Aquí imaginación y sentimiento son las facultades que tienen poder cognitivo, no el intelecto. Representarnos imaginativamente los males futuros, que se pueden derivar de nuestras acciones e invenciones del presente, hace movilizar nuestros sentimientos de miedo y temor ante las consecuencias de dichos males. Y es que, a juicio de nuestro autor, los males son siempre más perceptibles, imaginables y experimentables que los bienes: "nos resulta más fácil el conocimiento del malum que el conocimiento del bonum; el primero es un conocimiento más evidente, más apremiante, está menos expuesto a la diversidad de criterios y, sobre todo, no es algo buscado" (PR: 65).

En efecto, parece que sabemos mucho antes lo que "no" queremos que lo que queremos. De ahí que Jonas afirme que la filosofía moral ha de consultar a nuestros miedos más que a nuestros deseos y apetencias y hacerles más caso, con el fin de averiguar qué es lo que realmente apreciamos o no apreciamos. Y sabiendo que lo más temido es posible que no sea lo más digno de ser temido, tampoco ha de ser cierto que lo menos temido sea el mayor bien

${ }^{29}$ El principio de responsabilidad se podría muy bien calificar o incluir en las llamadas "éticas del riesgo", éticas propias de sociedades que se sienten bajo múltiples y difusas amenazadas o riesgos, como sugiere la obra del sociólogo Ulrich Beck. Cfr. BECK U.(2006), La sociedad del riesgo, Paidós,Barcelona. 
para nosotros. Aun entendiendo que la heurística del temor no tiene la última palabra en la búsqueda del bien, sí que debe tener la primera palabra en la evitación del mal. Llegamos aquí al corazón de la "ética orientada al futuro", cuyo primer deber es "procurar la representación de los efectos remotos"30.

El segundo deber que propone Jonas es el de crear en nosotros el sentimiento de temor a partir de la afección que en nuestra conciencia debe producir la representación imaginante que nos hemos hecho de los males o desgracias futuras que se pueden derivar de nuestros presentes o posibles actos:

Así, pues, aquí no puede tratarse, como en Hobbes, de un temor de carácter patológico" -para decirlo con Kant-, que nos asalta caprichosamente antes de que su objeto se presente, sino de un temor de carácter espiritual, que, como algo propio de nuestra actitud, es obra nuestra. La adopción de esa actitud esto es, la preparación para la disposición a dejarse afectar por una felicidad o por una desgracia solamente representadas de las generaciones veniderases, por tanto, el segundo deber "preliminar" de la ética aquí buscada, tras el primero de llegar a pensar así. (Ibid., p. 67)

La heurística del temor se hermana en Jonas con lo que pudiéramos llamar una profética de la catástrofe. Conviene no olvidar la naturaleza judía de nuestro pensador y el profundo conocimiento que poseía de la tradición judaica. Así, hemos apreciado en la obra de Jonas un talante y sentido proféticos: también los profetas advertían de las catástrofes que sobrevendrían al pueblo elegido si no cambiaban y corregían sus comportamientos. Creemos que es en esta tradición en la que cabe comprender el establecimiento que hace de un nuevo principio práctico según el cual merecen mayor credibilidad las profecías catastrofistas que aquéllas que anuncian futuros más halagüeños: "Planteándolo de forma elemental — dice—, se trata del precepto de que hay que dar mayor crédito a las profecías catastrofistas que a las optimistas" (PR: 71).

Ejemplificando esta cuestión, dentro del saber de lo posible, de lo "heurísticamente suficiente para la doctrina de los principios", Jonas va a prestigiar el valor heurístico de las narraciones de la "ciencia ficción", las que nos ayudan a anticipar de forma ficticia un futuro que, en muchas de ellas, aparece como catastrófico y posible:

La parte más seria de la ciencia ficción se basa precisamente en la realización de este tipo de experimentos mentales bien documentados, a cuyos resultados plásticos les puede corresponder la aquí mentada función heurística. (Véase, por ejemplo, Un mundo feliz, de A. Huxley). (Ibid., p. 69).

Con lo dicho, se entrevén las razones que Hans Jonas pueda esgrimir para sostener semejante precepto: la primera es que hay que conceder mayor peso a la amenaza —de males — que a la promesa — de bienes-; la segunda es que la aceleración de las innovaciones tecnológicas, su inercia y el dinamismo acumulativo que han alcanzado, no dejan ya tiempo para que se auto-regulen a sí mismas:

[...] las correcciones resultan cada vez más difíciles y la libertad de hacerlas es cada vez menor. Esto refuerza el deber de aquella vigilancia de los comienzos,

${ }^{30}$ Según reza el título del apartado I.4. del capítulo II de El principio de responsabilidad. 
que otorga a las posibilidades catastróficas serias y suficientemente fundadas diferentes a las meras fantasías pesimistas- la prevalencia sobre las esperanzas, aunque estas no estén peor fundadas. (Ibid.,p. 73)

\section{Del principio de responsabilidad al principio de precaución (Vorsorgeprinzip)}

El principio de precaución es lo que para Jonas significa "mandato de cautela" (PR: 72) — "das Gebot der Bedächtigkeit" (PV: 71)—o mandato de cuidado, lo cual es otro modo terminológico de hacer referencia al Vorsorgeprinzip, al principio de precaución ${ }^{31}$, hermano de la heurística del temor ${ }^{32}$. Recordemos que la figuración imaginante de la posible catástrofe, o catástrofes, ha de preceder al sentimiento del temor. Esta figuración o anticipación imaginanteemocional de un mal o males futuros tiene una virtualidad cognitiva, cuyo saber no es probatorio (es decir, no cabe la certeza de algo que todavía no ha ocurrido), pero del que sí que podemos decir que es un saber-sentimiento premonitorio, anticipatorio de aquello que no habiendo todavía ocurrido, puede ocurrir. Precaverse ante un mal posible, es no sólo un bien, sino una responsabilidad moral ${ }^{33}$.

Por su aplicación práctica cuasi ilimitada y su comprensión más común, elprincipio de precaución requirió de una sistematización, tanto filosófica como jurídica, que lo ha ido diferenciando de su acepción trivial y fundamentando también en unas cada vez más sólidas bases conceptuales. De todas maneras, esteprincipiosiempre ha estado ligado desde su inicio a prácticas conservacionistas del medioambiente en los distintos contextos humanos, sociales, económicos, políticos y jurídicos contemporáneos; prácticas tendentes a propiciar un desarrollo sostenible y solidario.

En su sentido cabal, esta categoría de "precaución" se liga a una nueva idea de

31 Para entender este "quantum" de "cuidado" que porta el principio de precaución cfr. el trabajo de François Guery, "La précautioncommesouci”, en ZARKA Yves Charles (ed.) (2012), Qu'est-ce que vaut le Principe de Précaution?, número monográfico de Revue de Métaphysique et de Morale, 4, pp. 611-621.

32 El Principio de precaución tuvo su aparición, entre los años sesenta y setenta del pasado siglo, en el ámbito de la jurisprudencia que trataba de regular los cada vez más escasos recursos marinos. "En su formulación explícita, el principio apareció primero en el campo de la protección del medioambiente y de la gestión de los recursos naturales, en particular en la gestión del entorno marino, dando testigo de ello el debate habido durante una década en el Marine PollutionBulletin. Esto tiene que ver con que el medioambiente es uno de los campos en los que las incertezas siguen siendo más importantes y más numerosas, al resistir a los procedimientos científicos por el mismo hecho de la complejidad de las interacciones en juego y del horizonte a largo plazo, que limitan el alcance de los procedimientos experimentales. Las primeras formulaciones explícitas del principio como principio de política pública fueron adoptadas en Alemania, al final de los años setenta, con el nombre de 'Vorsorgeprinzip'." Transcripción nuestra al castellano de su original en gallego que se puede consultar en HOTTOIS Gilbert y MISSA Jean-Nöel (2005), "Precaución (Principio de)”. En Nova Enciclopedia de Bioética, Servicio de Publicacións da Universidade de Santiago de Compostela, Santiago de Compostela, p. 701. Para una reflexión más profunda sobre "el principio de precaución", cfr. MISSA J. N. y ZACCAI E. (eds.) (2000), Le principe de précaution. Signification et conséquences, Editions de L'Université de Bruxelles, Bruxelles.

${ }^{33}$ Si nuestras acciones actuales aparecen preñadas de riesgos, sería de locos irresponsables no tomar cautelas y controles racionales respecto de sus posibles consecuencias. 
comportamiento humano en su relación de equilibrio y sostenibilidad con el entorno. Sus fundamentos teóricos sirven de impulso a su dimensión activa y pragmática. Fundamentos que deben ayudar a definir y a regular los límites de la incertidumbre y del riesgo mediante nuevas modalidades de cómputo temporal de los efectos de las acciones humanas. De este modo se genera un concepto alternativo de "racionalidad responsable", capaz de abordar el futuro y sus riesgos con el concurso de la ética y de la acción política.

Esteprincipio presupone y fomenta virtudes privadas y públicas - políticascomo la responsabilidad, el respeto, la prevención, la obligación de saber e informar y la obligación de compartir el poder, es decir: las deliberaciones, decisiones y acciones sobre los asuntos públicos. Pero como principio en ciernes, esta idea se puede prestar a tergiversaciones y utilizaciones oportunistas que generan su descrédito. Así sucede con la ideología denominada "precaucionismo", resultado de un neopopulismo refractario al interés general, del mismo modo que con el "catastrofismo", diferenciable éste de una equilibrada y razonada ponderación de los riesgos. Tanto el catastrofismo como el precaucionismo, en sí extremistas e irracionales, adulteran el sentido recto del principio de precaución -ya que lo reformulan inadecuadamente en aras de intereses ajenos a su propia coherencia científica y social-, y son causantes de un espejismo colectivo de posibles graves consecuencias $^{34}$.

Evidentemente, el principio de precaución no es lo mismo que la prevención; ésta es posible cuando se conocen con certeza los riesgos. Hablamos de precaución cuando estos riesgos no se conocen o son inciertos. El principio tampoco pretende anular todos los riesgos, aunque sí la efectiva reducción de los mismos. Por tanto, no se trata de que la precaución invierta la llamada «carga de la prueba» ${ }^{35}$.

La precaución ni supone una evaluación negativa de la tecnociencia, ni tampoco una restricción a la investigación; lo que sí exige es una clara conciencia de la responsabilidad en todas las fases del proceso tecnocientífico y productivo ${ }^{36}$. Pero ante la confusión, se puede proponer una categoría intermedia, el espíritu de precaución,denominación provisional para un concepto que requiere ser madurado hasta alcanzar carácter sistemático y superar la fase lógica y normativa, lo que obedece a la urgencia de las preocupaciones ecológicas.

\footnotetext{
${ }^{34}$ Para un buen análisis de ambas posiciones, véanse los trabajos de Gérald Bronner, "Perceptions du risque et précautionnisme" y de Olivier Godard, "La politique des risques peutelle être raisonnable? Le principe de précaution et ses déboires". En Révue de Métaphysique et de la Morale, 2012, 4, pp. 531-547 y pp. 511-529 respectivamente.

${ }^{35} \mathrm{El}$ que se exija "la prueba de la inocuidad de un producto para ponerlo en el mercado. Si una prueba así fuera posible, respondería a una especie de lógica de la prevención absoluta, basada ya no en la incertidumbre de la nocividad, sino en la de la inocuidad". (2004) BOURG, D. y SCHLEGEL, J-L., Anticiparse a los riesgos, Barcelona, Ariel, p. 147.

${ }^{36}$ Conciencia que ha llegado así a la ciencia: el «Programa de acción en pro de la ciencia (marco general de acción)» fue aprobado en la Conferencia Mundial sobre la Ciencia (1999). Ello vino precedido de la declaración de Wingspread de 1998 donde un conocido grupo internacional de investigadores definió y fomentó el concepto. Cfr. RIECHMANN J. y TICKNER, J. (2002), El principio de precaución. En medio ambiente y salud pública: de las definiciones a la práctica, Icaria, Barcelona, pp. 18s.
} 
Sin duda, el principio de precaución resulta una actitud cívica y social con la que regir las obligaciones de individuos y empresas, pero sobre todo es un principio que debe regir una ética de las políticas públicas con el objetivo de lograr una sociedad sostenible. La aplicación práctica de esta doctrina debe sobreponerse al descrédito venido de las connivencias que existen entre empresas, poderes políticos, comités científicos de asesoramiento e incluso poderes judiciales, nacionales e internacionales, que a menudo son excesivamente condescendientes con los delitos medioambientales. Por el contrario, su aplicación debe sustraerse a todo propósito manipulador de la opinión pública por parte de las administraciones públicas y empresas privadas para fundamentarse en informaciones contrastadas y veraces ${ }^{37}$, en disposiciones normativas no sólo democráticas y legítimas sino efectivas y cuyo incumplimiento lleve aparejadas sanciones económicas y administrativas acordes a los posibles daños y riesgos.

\section{Valoración crítica del pensamiento de Jonas a la luz de la conciencia ecológica}

Antes de pasar a un posicionamiento crítico del principio de responsabilidad conviene realizar una síntesis conclusiva de este principio desde el pensamiento de Jonas.Él considera, por una parte, que el progreso tecnológico ha revelado que la amenaza va unida a la promesa de una vida futura mejor. Por otra, semejante desarrollo supone un reto interno para el hombre que afecta a la permanencia de su propia naturaleza y a la del resto de los seres vivos. Según Jonas, la tradicional sabiduría no tiene respuestas para ello, así como tampoco la tienen ninguna de las éticas habidas hasta ahora ya que estando secularmente dedicadas a la relación entre iguales $-\mathrm{y}$, por eso, siendo "antropocéntricas", al criterio de nuestro autor- resultan absolutamente incapaces de fundamentar y arbitrar una normatividad de las relaciones hombre-naturaleza a la altura de semejante desafío. No existe la neutralidad axiológica de la tecnología, pues —según él-no hay conocimientos "desinteresados". Se impone, por tanto,una llamada a la asunción del sentido de la responsabilidad -específica, ampliada- por parte de los diferentes agentes sociales, tanto teóricos como científicos y, sobre todo, poderes públicos. Se debe entender que el hecho de que el ser humano y toda la Tierra estén amenazados resulta una gran novedad a la que se debe enfrentar la ética. Este novum obliga a expandir los principios éticos: la responsabilidad presente es la que ha de garantizar la libertad futura, esto es, que el futuro permanezca abierto para las generaciones venideras. En contra de la idea cartesiana, aquí lo dudoso adopta la fuerza de la certeza. Por eso Jonas va a defender los criterios de precaución y de responsabilidad ética -entendida como una responsabilidad consiciente, incondicional y no basada ni en la buena fe ni en la reciprocidad-, elaborando una concepción anti-utópica del obrar humano y de la historia, sobre la base de una sabiduría que él denomina "heurística del temor". Este temor o miedo, contrariamente a las filosofías clásicas, no impide sino que requiere del propio ejercicio de la responsabilidad. $Y$ estees el primer paso para una ética orientada al futuro, donde el primer

\footnotetext{
${ }^{37}$ Un ejemplo cercano es el caso de la propaganda "verde" de la papelera ENCE-Pontevedra en los medios de comunicación, un claro ejemplo de manipulación informativa.
} 
deber es "procurar la representación de los efectos remotos" de nuestras acciones y donde el segundodeber es crear en nosotros el sentimiento de temor a partir de la afección que en nuestra conciencia debería producir la representación mental que nos hemos hecho de los males o desgracias futuras que pueden derivarse de nuestras acciones presentes. En definitiva, la ética del riesgo que Jonas predica esel deber de la autolimitación y del autocontrol ante las amenazas y riesgos que provocan el sistema económico desarrollista y también las nuevas tecnologías. Y aquí es, a mi juicio, cuando debe entrar en escena el llamado principio de precaución, en el que juega un papel central el mismo sentimiento de temor y consiguiente preocupación, lo que no significa un sentimiento de angustia. Estamos ante la responsabilidad de precaverse ante el mal posible. Cuanto más oscura y alejada en el futuro esté la respuesta, mayor será la incertidumbre y más aguda deberá ser la heurística del temor; un temor no paralizante sino activo, sinónimo de respeto y de cuidado.

Por otro lado, en la dimensión derivada de la conciencia ecológica, sabemos que la pretensión ecoética de llegar a una relación armónica entre el ser humano y la naturaleza se basa en dos principios fundamentales. Uno es la ecodependencia. En este sentido, sin duda, la orgánica fundamentación jonasiana sintoniza con el hecho de que cualquier organismo debe ser puesto en valor por sí mismo ${ }^{38}$, e incluso coincide cuando especifica que "la causalidad final se halla presente también en la naturaleza preconsciente", que "el ser -o la naturaleza- es uno y da testimonio de sí en aquello que él deja que emerja de sí" ${ }^{39}$. Ahora bien, otra cuestión es el rango de dignidad que Jonas le otorga. Lo que la ecoética admite es una clara dignidad natural asociada a cualquier organismo pero lo más decisivo -para nuestra argumentación-, y éste es otro de sus principios fundamentales, su punto de vista esbiocéntrico.

En PR, Jonas lo que nos está diciendo es que su ética no puede ser calificada de antropocéntrica ${ }^{40}$. Realmente nos quedó claro que no lo es en el sentido de las éticas anteriores, las que se limitan a medir y regular la relación del mal entre las personas. Pero para valorar la sostenibilidad de su consideración vayamos al propio textodel Principio de responsabilidad:

\footnotetext{
${ }^{38}$ Una obra complementaria y en extremo útil para entender mejor los fundamentos filosóficobiológicos y metafísicos de la ética jonasiana y, en concreto, de El principio de responsabilidad, es su obra publicada en 1994 bajo el título Das PrinzipLeben. AnsätzezueinerphilosophichenBiologie, InselVerlag, Frankfurt am Main und Leipzig.Hay traducción al español: (2000) JONAS, H., El principio vida. Hacia una biología filosófica, Trotta, Madrid. En esta obra el autor presenta una concepción filosófica del mundo "orgánico" según la cual éste aparece como fundamento o condición de posibilidad de "lo espiritual", tratando de elaborar un pensamiento que supere el viejo dualismo de materia y espíritu.

${ }^{39}$ PR: 128.

${ }^{40}$ Según Wolin: "la implícita critica de Jonas del antropocentrismo -su denigración de la preeminencia de la humanidad en la jerarquía natural- halló gran resonancia en el movimiento pacifista alemán. Así, su afirmación de que «la naturaleza no podría haber corrido un peligro mayor que el producir al hombre» podría haber servido como credo al ala fundamentalista del movimiento". WOLIN, R., op. cit., p. 189. También, en opinión dePablo Arcas, "ciertamente, anticipando lo que pretendemos defender, la ética jonasiana no es antropocéntrica, pero sí antropológica pues, al fin y al cabo la obligación sigue siendo humana". (2007) ARCAS P., Hans Jonas y el Principio de responsabilidad: del optimismo científico-técnico a la prudencia responsable, 
La naturaleza, en cuanto responsabilidad, es sin duda un novum sobre el cual la teoría ética tiene que reflexionar [...] En la medida en que es el destino del hombre, en su dependencia del estado de la naturaleza, el referente último que hace del interés en la conservación de ésta un interés moral, también aquí ha de conservarse la orientación antropocéntrica de toda la ética clásica. (PR: 33)

Como se ve,al hacer referencia a la orientación antropocéntrica de toda ética clásica, Jonaspronto se descubreuna cierta defensa del antropocentrismo al indicarnos queesta orientación "ha de conservarse" respecto a la relación del hombre con la naturaleza.

En otro texto de su famosa obranos encontramos con su previo rechazo alantropocentrismo pero donde añade un importante matiz: según Jonas deberíamos cuando menos de someter el antropocentrismo a ciertos límites para que no actúe como una base teórica que permita un uso de la tecnología conducente a la destrucción de la vida planetaria y, como consecuencia, de la vida humana:

[...] No puede permanecer anclada en el desconsiderado antropocentrismo que caracteriza a la ética tradicional $y$, especialmente, a la ética occidental helénico-judeo-cristiana. Las posibilidades apocalípticas que hay en la tecnología moderna nos han enseñado que el exclusivismo antropocéntrico podría ser un principio y que, al menos, precisaría una revisión. (PR: 99)

En lo que semeja ser un posicionamiento con respecto al antropocentrismo que se va mostrando como en gradación, finalmente Jonas, en este mismo texto pero mucho más adelante, sin embargo parece desmarcarse totalmente de aquél. Primeramente lo defendía; después, decía que había que tenerlo bajo control y limitarlo; ahora, en el siguiente fragmento, parece insistir en la necesidad de alejarse de él:

El futuro de la naturaleza es de suyo una responsabilidad metafísica, una vez que el hombre no sólo se ha convertido en un peligro para sí mismo, sino también para toda la biosfera. Incluso si pudiéramos disociar ambas cosas esto es, incluso si fuera posible para nuestros descendientes una vida que pudiera llamarse humana en un mundo devastado ( $y$ en su mayor parte reemplazado artificialmente)-, la rica vida de la Tierra, producida en una larga labor creativa de la naturaleza y ahora encomendada a nosotros, exigiría nuestra protección. Dado que de hecho no es posible separarlas (a menos que convirtamos al hombre en una caricatura $)^{41}$ y dado que en lo más decisivo esto es, en la alternativa "conservación o destrucción"-el interés del hombre coincide con el del resto de lo vivo en cuanto es su morada terrena en el más sublime de los sentidos, podemos contemplarambos deberes como uno solo bajo la idea del deber para con el hombre, sin por ello caer en el reduccionismo antropocentrista. (PR: 227)

Si Jonas hubiera visto la cinta cinematográfica SilentRunning -siete años anterior al PR-,quizá podría "imaginar" la posibilidad de un mundo sin la naturaleza que conocemos y donde el hombre puede seguir siendo tan

\footnotetext{
${ }^{41}$ De momento, la realidad nos lleva a poder aseverarcon rotundidad que la caricatura que sí encontramos hoy es en lo que hemos convertido la naturaleza; el cerebro y resto de constitución física y esencial del ser humano no ha cambiado nada en los últimos miles de años a pesar de todos los cambios tecnológicos. (Vid. nota 43).
} 
esencialmente necio o virtuoso como hasta ahora ${ }^{42}$. De hecho, a pesar de los esfuerzos del conservacionismo y del movimiento medioambientalista, seguimos en la senda de una progresiva artificialización sin freno a la vista ${ }^{43}$. ¿Por qué no podría acabar todo en semejante distopía?Aunque no sea así, simplemente teniendo en cuenta el valor heurístico de las narraciones de la "ciencia ficción", esto es, siguiendo la misma argumentación que vivos enJonas al hablar de la heurística del temor, deberíamos imaginar semejante "profecía catastrofista" pues, con ello reforzamos, como decía,"el deber de aquella vigilancia de los comienzos, que otorga a las posibilidades catastróficas serias y suficientemente fundadas -diferentes a las meras fantasías pesimistas- la prevalencia sobre las esperanzas, aunque éstas no estén peor fundadas" ${ }^{44}$.

En cualquier caso, lo que importa a Jonas es evidente: "El primer deber del comportamiento humano colectivo es el futuro de los hombres" (PR: 227). Pero, entendemos que el hecho de quela obligación moral siga siendo humana no implica que ambos deberes — hacia la naturaleza y hacia las personas-deban estar bajo la idea del deber para con el hombre,pues ello equivale adejaral ser humano en el lugar privilegiado que siempre se ha otorgado a sí mismo. Sin duda, la éticade la responsabilidad es antropológica y ecológica pero, a pesar los argumentos disuasorios de Jonas, adolece de un claro "reduccionismoantropocentrista".Hottoisasí lo confirma cuando pone de relieve que la fundamentación metafísica de Jonasaupaal hombre como la finalización de la evolución ${ }^{45}$.

Aunque, como hemos apuntado, el principio de reponsabilidad de Jonas ha ayudado a cimentar el camino de la conciencia ecológica, hoy en día este

\footnotetext{
${ }^{42}$ La acción se produce en un cierto futuro, en el final de la vida vegetal de la Tierra por la contaminación y el calentamiento global. Sólo se conserva una muestra de la diversidad natural en tres naves espaciales, cuya misión es volver a repoblar la Tierra cuando ello fuera conveniente. La tragedia final deviene con las órdenes dadas desde Tierra, de destruir los "domos", los cubículos contenedores de flora y fauna que portan las naves espaciales, con vistas a reutilizarlas para el servicio comercial. La necedad viene representada por dos de los tres comandantes que harán caso a tales órdenes, con muy poco aprecio por el incalculable tesoro que tienen a su cuidado; el comandante de la tercera nave mostrará la encomiable virtud de entregar su vida por preservar la preciosa carga de su nave, la que así acabará vagando por el espacio a la espera de poder injertarla vida en algún otro lugar del universo en el que no haya una especie tan conscientemente perniciosa como la nuestra.

${ }^{43}$ ¿Qué es hoy la naturaleza? Dos grandes selvas en constante recesión y una limitada red de reservas naturales, en general, agobiadas por la industria turística, acosadas por intereses energéticos y especulativos como los responsables de la misma destrucción selvática. La naturaleza hoy, sobre todo, es -0 va camino de ser- poco más que parques y jardines, bosques monocultivo y mares y terrenos sobreexplotados. Todo ello aderezado por la comentada contaminación "por tierra, mar y aire". Hoy la naturaleza está mancillada a tal nivel que podríamos afirmar queella es poco más que mero artificio humano. Como advertíamos, la naturaleza es una caricatura de lo que ha sido en la mayor parte de su historia (vid. nota 46).

${ }^{44}$ PR:73. Definitivamente, la argumentación de Jonas, en su intento de evitarle a su ética de la responsabilidad la adjetivación de antropocéntrica, puede encontrar su epitafio con la misma pregunta que él se hace bien pronto: "¿Se trata simplemente de la prudencia que nos prohíbe matar la gallina de los huevos de oro o cortar la rama sobre la que uno está sentado?". (Ibid., p. 33).

${ }^{45}$ (1993) HOTTOIS G., "Une analyse critique du néo-finalismedans la philosophie de $\mathrm{H}$. Jonas". En HOTTOIS G., y PINSART, M. G. (eds.), Hans Jonas. Nature et responsabilité, Vrin, Paris, p. 34.
} 
despertarde poco sirve si no está informadoporla ecoética. Y como se ha advertido, la ecoética o es biocéntrica o no es ecoética. Atendiendo al valor que pueda tener para ésta, el principio de responsabilidad resulta un tanto limitado, cuando no obstaculizante,para el asidero que va ganando terreno en la conciencia colectiva actual, el de la dignidad de la naturaleza, su integridad esencial y existencial de la que es parte el ser humano. Se puede recordar que ya, con la misma arqueología de la conciencia ecológica, con $\mathrm{H}$. D. Thoreau y con la aparición del conservacionismo, en el siglo XIX,el antropocentrismo empezó a dar incipientes pruebas de desgaste ${ }^{46}$.En el siglo XXI no resulta tan extraño, entonces, afirmar que ya se ha ganado un bien merecido descanso ${ }^{47}$.

En lo que sigue, vamos a hacernos eco de algunas críticas de aspectos no menos controvertidos de la obra de Jonas. Por un lado, dirá Apel, refiriéndose a este autor,que el problema de desaparición es para el ser humano y los animales o vegetales más importantes ${ }^{48}$, no para el conjunto de la naturaleza. $Y$ es cierto, sin duda. En los comienzos de la vida se hallaban microorganismos como las bacterias, los mismos que son parte constitutiva del organismo humano y que seguirían existiendo aunque desaparezcan todos lo animales y vegetales importantes.Este autor también denuncia que no hay en Jonasuna suficiente diferenciación criteriológica de unos seres respecto de otros en su fundamentación metafísica. Por otro lado, en ese ámbito, se pone de manifiesto que el deber de respetar la igualdad de derechos de todos los seres humanos vivos hoy no tiene el mismo rango metafísico que el deber de salvaguardar las condiciones de existencia de la humanidad futura.

\footnotetext{
46 "Fui a los bosques porque quería deliberadamente, enfrentarme sólo a los hechos esenciales de la vida y ver si podía aprender lo que la vida tenía que enseñar, y para no descubrir, cuando tuviera que morir, que no había vivido". Una experiencia irrepetible hoy en día. (2005) THOREAU, H. D., Walden, Cátedra, Madrid, p. 137.

${ }^{47}$ La existencia de la naturaleza, esa que Hans J. pone en segundo término, "En la era de la civilización técnica, que ha llegado a ser 'omnipotente' de modo negativo, el primer deber del comportamiento humano colectivo es el futuro de los hombres" (PR:227), y a la luz de la conciencia ecológica, ahora lo que precisa es que el ser humano dé un paso más allá para su preservación. No es tolerable permitir una contradicción como esta: la humanidad amenaza la vida en la Tierra pero el bien máximo a preservar es la misma humanidad. Así, la naturaleza es sólo la rama en la que nos apoyamos. El choque con el biocéntrico principio es evidente; para la ecoética, la humanidad debe volver a poner a la naturaleza como medida de todas las cosas para, así, también poder garantizar -pero en segundo término- su supervivencia. (¡Y en caso de merecerlo! No abordamos, de momento, este tema por falta de extensión; con ello vamos más allá en las dudas a las conclusiones metafísicas jonasianas, donde el sentido y la propia existencia humana resultan absolutamente intocables). Estamos, pues, ante un ser muy especial, el homo sapiens, particularmente interactivo e hiperactivo, pero que sólo ocupa un período insignificante en la historia de la vida y cuya grandeza muy pronto ha mostrado su peor cara. Sin duda, se trata de un ser vivo más, —un ciudadano más de la comunidad biótica -(1997) G. Gómez HERAS, J. M. (ed.), Ética del medio ambiente. Problemas, perspectivas, historia, Tecnos, Madrid-, absorto en su propio mundo, pero que acabará por extinguirse de una u otra forma en algún momento futuro. Mientras tanto, cuidar de la existencia de la naturaleza ( $\mathrm{y}$, cómo no, de su esencia, en sentido metafísico) es la única posibilidad que tiene el ser humano para que perviva él mismo, y así también su esencia, la "imagen fiel" del hombre que preconiza Jonas. $\mathrm{Y}$ es que, por ejemplo, no parece coherente permitir el consumo de productos transgénicos -sabedores o ignorantes de sus negativas consecuencias-, mientras se pone el grito en el cielo por la modificación genética o mecánica de los humanos, dadas las imprevisibles consecuencias para su "sagrada" esencia. Si no procede lo uno, no procede lo otro. Pero digamos, también, y viceversa.

${ }^{48}$ Cursivas nuestras.
} 
Por su parte, Hottois denuncialas deficiencias de la argumentación de Jonas: el escasamente justificado paso de la ontología a la metafísica, interrumpida en lo que seguramente es un abrupto giro intuicionistadebido al vitalismo que en un momento dado emergesin remedio de su fundamentación ética ${ }^{49}$. Vitalismo que, según Wolin, significa darprioridad a la "mera vida" —es decir, a la supervivencia- por encima de la "buena vida". Como en Hobbes-por más queJonas se desmarque de él-, estamos ante una antropología metafísica pesimista, donde el miedo marca la pauta;peroaún más, donde hay que añadir el tono apocalíptico yuna inevitable resignación. Wolin también rechaza la concepción de libertad que Jonas utiliza en su fundamentación biológicoontológico-metafísica. Así, dirá que "sugerir afinidades entre libertad y metabolismo supone que nos contentemos con una idea subhumana de lo que conlleva la libertad" ${ }^{50}$.

Muy diferente, y más positivo,hubiera sido el resultado si, en vez de partir de la biología lo hubiera hecho desde la vida en sociedad.Arendt así se lo hizo saber a Jonasinmediatamente después de su positiva sentencia (vid. nota 16). Ella desaprobaba de modo tajante el que la responsabilidad elemental del ser humano pudiera estar fundada biológicamente,o sea, a partir del orden natural. Para Arendt, más bien se trata de una relación de convivencia libremente establecida, nacida en la polis, en el marco del Estado, que es política y no de familia. Arendt se remitía a Aristóteles,quiendistinguía entre la esfera privada de la unión familiar y la esfera pública de la comunidad de la polis. Igualmente afirmaba Arendtque algo así como "la responsabilidad para con el bien común era, por naturaleza, artificial y antinatural, y que en la tradición occidental se debía al "contrato social'»" ${ }^{51}$.No en vano, Jonas aplicará sus reflexiones éticas en tono apocalípticoa la política, unasreflexiones de las que se entrevé unpremoderno paternalismo y una consecuente desconfianza hacia la democracia liberal.Desconfianza que llega, prácticamente a ser un rechazo; a lo mejormerecido, en cierta manera, pero aderezado por una rigidez que va a derivar enuna defensa de la autocracia. Al fin y al cabo, sus posicionamientos éticos categóricos-como los de su maestro Heidegger-,presuponen más la aquiescencia que el debate.Por ello están en las antípodas de posiciones como las de Habermas o las del mencionado Apel, éticas comunicativas de la deliberación y de la decisión que, en este aspecto, sintonizarían mejor con una conciencia colectiva verdaderamente solidaria y democrática ${ }^{52}$.

\footnotetext{
${ }^{49}$ Cfr. la tesis de Pablo Arcas Díaz para entender el tránsito de la ética a la metafísica que realiza Jonas, y para más información sobre estas críticas de Apel, Hottois, etc. ARCAS, P., op. cit., pp. 226-230.

${ }^{50}$ WOLIN, R., op. cit., p. 184.

51 (2005) JONAS H., Memorias, Editorial Losada, Oviedo, p. 351.

52 "La concepción de la naturaleza de Jonas, mezcla de aristotelismo y evolucionismo, sin contingencias ni discontinuidades, deja en suspenso el principio kantiano de universalización de la justicia. La pragmática-trascendental de Apel, desde un kantismo renovado y abierto, ofrece una alternativa moderna al neofundacionalismo metafísico jonasiano, y salvaguarda el principio. A la vez, permite definir la responsabilidad como co-responsabilidad, subrayando el carácter intersubjetivo de todo acto moral, obviado en el subjetivismo jonasiano, y a la vez dejando vía libre al establecimiento de obligaciones derivadas hacia la naturaleza. Apel muestra el error que supone olvidar la historia de la ética, aun en momentos de crisis, pero no que 'una nueva ética de la responsabilidad no sea necesaria o que no deba ser diferente del tipo clásico de éticas abstractas de principios deónticos'. El problema de la praxis, evitado en el
} 
En lo que sí estamos con Jonas, y con la tradición crítico-filosófica,es en el hechode que la humanidad ha cruzado un umbral muy peligroso, conferido por un poder sin precedentes venido de la razón tecnocientífica. Por más que la técnica sea constitutiva de nuestro ser (la forma idiosincrásicamente humana de crear e interpretar el mundo), los avances de la tecnología tienen necesariamente que tener límites para conservar la existencia y la autenticidad de la vida. Pero es más, el temor y la incertidumbre que para la pervivencia de la humanidad se deriva de la naturaleza ya no tiene parangón con el constante peligro que para la vida de toda la biosfera supone la actividad humana. En un entorno en el que se crean necesidades a partir de meros deseos, con imprevistas e imprevisibles consecuencias, las nuevas invenciones precisan de la criba de una nueva ética,es decir, precisan de la responsabilidadpero en el sentido del espíritu de precaución. La idea de no igualdad entre progreso y desarrollo debería hacer del hermano de la heurística del temor - es decir, del principio de precaución - el axioma de gestión sostenible futura tanto de la producción y uso tecnológicos como de las actividades económicas productivas y de consumo. La idea de precaución ala que nos hemos referido no debe significar en ningún momento una abstención irrestricta, sino la gestión activa y responsable del riesgo: debería consistir en asumir que el conocimiento humano sobre las consecuencias de nuestras acciones suele ser incierto, débil e incompleto, y que actuar en contextos de incertidumbre o ignorancia debe obligar a extremar la precaución para evitar posibles males mayores.La aplicación generalizada del principio de precauciónlegitimaría, así, las nuevas invencionesy ayudaría a que la humanidad recobrase cierta dignidad perdida y hasta la razón de su existencia.Hablamos de prudencia responsable, del espíritu de precaución, el más eficaz servicio a la conciencia ecológica, auténtica solidaridad para con las generaciones futuras de todas las especies.

En definitiva, recogemosasí la preocupación jonasiana pero en clave ecoética, sintetizado todo ello en lo que hemos querido llamar como conciencia precautoria. 